\title{
ENTRE CIDADES, FAMÍLIAS E REDES DE PERTENCIMENTOS: PESQUISA ANTROPOLÓGICA E ETNOGRÁFICA SOBRE AS TRAJETÓRIAS, ITINERÁRIOS, ESTILOS E PROJETOS DE VIDA DE ESTUDANTES UNIVERSITÁRIOS RESIDENTES EM PORTO ALEGRE ORIUNDOS DE CIDADES INTERIORANAS.
}

\author{
Fabiela Bigossi \\ Cornelia Eckert ( Orientação).
}

Este trabalho evidencia o desenvolvimento de pesquisa etnográfica no campo de conhecimento da antropologia urbana e/ou na cidade moderno contemporânea brasileira, para dar conta do processo vivenciado pelos estudantes universitários oriundos das cidades interioranas, que compreende a formulação de um projeto familiar (VELHO, 2003) de mudança da cidade onde morava com os pais para passar a morar na capital a fim de desenvolver estudos universitários, e dessa forma analisar as transformações no estilo de vida que passam a ocorrer na vida do estudante a partir do momento em que ele passa a residir longe da rede de sociabilidade do interior que o envolvia. Para tanto, a metodologia qualitativa, através do uso da etnografia foi utilizada para compreender o objetivo que está sendo proposto.

Esta pesquisa teve início em março de 2004, quando estava no quinto semestre do curso de Ciências Sociais como atividade individual de pesquisa como bolsista de Iniciação Científica PIBIC/CNPq no Projeto de Antropologia Visual, desenvolvido pelo Núcleo de Antropologia Visual e coordenado pela Profa. Dra. Cornelia Eckert.

O trabalho antropológico pressupõe o distanciamento ou familiarização do antropólogo com o objeto de pesquisa escolhido para compreender as visões de mundo e estilos de vida do grupo que está sendo estudado, hoje, onde cada vez mais se faz pesquisa na sociedade em que nos encontramos inseridos, ou seja, familiarizados necessita-se tornar estranho o que nos é tão presente no dia-a dia. A preocupação nessas pesquisas é dar conta desse distanciamento do objeto escolhido, necessário para a realização do trabalho entre grupo de pertencimento, estranhando para perceber o seu ethos. Como aponta Da Matta (1978:28): “... o problema é, então o de tirar a capa de membro de uma classe e de um grupo social específico para poder - como etnólogo - estranhar alguma regra social familiar e assim descobrir o exótico no que está petrificado dentro de nós pela reificação e pelos mecanismos de legitimação". 
Dessa forma, procurei estranhar um universo de pesquisa no qual me encontro inserida, pois assim como meus informantes me dirigi do interior para a capital para cursar uma faculdade.

Essa mudança de uma cidade do interior para a capital fazia parte de um projeto familiar que incluía a passagem pela universidade e especificamente pela UFRGS, devido a qualidade e gratuidade do ensino. Esse projeto fora construído e discutido na família intensamente durante os três anos que antecederam a vinda para a capital e em torno desse objetivo de transferência de cidade foram feitas as constantes reconstruções do projeto.

A rede de informantes foi formada em princípio por colegas e amigos do curso de ciências sociais que se dispuseram a contar sobre sua trajetória ${ }^{1}$, expandindo-se ao longo da pesquisa para estudantes de outras áreas que foram, para mim apresentados, por colegas que já faziam parte da pesquisa, por serem pertencentes a sua nova rede de conhecidos formada a partir do ethos universitário, mas não necessariamente procedentes da mesma cidade (BOTT, 1976). A utilização das histórias de vida dos informantes é necessária para a construção de suas trajetórias de vida e compreensão de aspectos subjetivos da vivência de cada um, dentro de um sistema de valores e de representações que digam respeito a como se construiu um projeto de vida de vir estudar na capital.

A pesquisa etnográfica tem por base a concepção de que os comportamentos humanos são devidamente compreendidos se estudados no seu contexto e para tanto se pressupõe compreender a visão de mundo do nativo, procurando o significado de suas práticas. Dessa forma a abordagem etnográfica consistiu na observação do ambiente e cotidiano desses estudantes, nas entrevistas realizadas com eles e na construção de suas trajetórias.

A escolha pelos estudantes se deu também devido a possibilidade de encontrar nesse grupo estilos de vida diferenciados no que se relaciona ao estilo de morar na capital, dessa forma, são investigados estudantes que moram com parte da família, com amigos que já conheciam quando vieram do interior, com amigos que conheceram aqui, aqueles que moram sozinhos e por fim aqueles que tem seu cotidiano ligado a casa de estudante. 
Conhecer o estilo de vida ${ }^{2}$ dos estudantes interioranos implicou em acompanhar seus cotidianos através da observação participante em Porto Alegre e também no interior, indo até suas casas ou acompanhando-os em lugares onde gostariam de ser entrevistados. A negociação para a realização da pesquisa com os informantes e seus familiares se dava com a explicação, por parte do pesquisador, do que seria questionado e mencionado o trabalho que resultaria nesta pesquisa que eles estavam participando. Não houve nenhuma aceitação problemática, tanto por parte dos estudantes quanto de seus pais, esses últimos eram sempre comunicados primeiramente pelos filhos e após essa aceitação havia então o encontro com a pesquisadora que falava novamente sobre o tema do trabalho. A entrevista realizada com os pais de uma estudante no interior foi realizada no período de férias escolares, quando aproveitei a ida da estudante para o interior e acompanhei-a em visita a seus pais.

Foram realizadas dez entrevistas semi-estruturadas com a utilização do gravador, oito sem a utilização do gravador e inúmeras conversas informais, principalmente com aqueles estudantes com os quais meu contato era quase que diário. A utilização de entrevistas semi-estruturadas permite que o entrevistado detenha, além do entrevistador, a possibilidade de exploração do tema, e também é possível adentrar nas respostas de conteúdo afetivo recebidas do entrevistado. A realização das entrevistas com a utilização do gravador foram privilegiadas no início da pesquisa, quando foram ouvidas as histórias de vida e construídas as trajetórias dos informantes. As entrevistas com os pais dos informantes também foram realizadas com a utilização do gravador. As entrevistas semiestruturadas que não foram gravadas são aquelas em que eu retornava a campo após a leitura dos diários e discussões de orientação onde percebia a ausência de alguns elementos importantes para a composição da pesquisa e por isso necessitavam serem contemplados.

Para a realização desta pesquisa etnográfica foram desenvolvidas as trajetórias de sete estudantes universitários de diversos cursos, vindos de fora da região metropolitana de Porto Alegre, onde enfoco a partir das entrevistas e das imagens fotográficas seu

\footnotetext{
1 "Trajetória é a série de posições sucessivamente ocupadas pelo mesmo escritor em estados sucessivos do campo literário, tendo ficado claro que é apenas na estrutura de um campo, isto é, repetindo, relacionalmente, que se define o sentido dessas posições sucessivas, publicação em tal ou qual revista, ou por tal ou qual editor, participação em tal ou qual grupo etc" (BOURDIEU, 1996:71)

2"Estilo de Vida é um conjunto unitário de preferências distintivas que exprimem, na lógica específica de cada um dos subespaços simbólicos, mobília, vestimentas, linguagem ou héxis corporal, a mesma intenção expressiva, princípio da unidade de estilo (...)" (BOURDIEU, 1983:83)
} 
deslocamento residencial, analisando as mudanças no estilo de vida, as relações intrafamiliares e as tensões e conflitos neste processo que implica na cultura do viver na cidade, conforme George Simmel, "estilo metropolitano de vida” (SIMMEL, 1973).

A busca e levantamento de informações se deram através da técnica de observação participante, com utilização de equipamento fotográfico, entrevistas semi-estruturadas e ainda a construção das histórias de vida e trajetória dos estudantes.

A observação participante da moradia e da sociabilidade dos informantes foi a técnica escolhida para dar conta das questões acerca do processo de construção de um estilo de vida enquanto estudante universitário vivendo distanciado do núcleo familiar ascendente, buscando conhecer a forma como valores de autonomia, liberdade, profissionalização individual, menor controle moral, complexificação e diferenciação das redes e pertencimentos sociais de sociabilidade no contexto universitário configuram, no estilo de viver o projeto universitário bem como os valores e formas de sociabilidade familiar e de parentesco, estruturas prescritivas (Sahlins, 1990) para o jovem universitário, seja como continuidade de identidade afetiva seja de forma mais conflitiva pela distinção que se constitui nesta experiência de afastamento em termos de valores ideológicos, políticos e culturais constitutivo de situações de ambigüidade e mesmo conflito entre o projeto familiar e o projeto individual do estudante pela demanda familiar de retorno sistemático e jogos morais na busca de controle do processo individualizante do jovem em relação a sua família de origem e da qual depende financeiramente para sobrevivência e continuidade do projeto de profissionalização .

As fotografias são um estudo etnográfico pela imagem de construção das trajetórias dos estudantes numa perspectiva analítica comparativa da vida cotidiana nestes dois espaços de vivência do estudante, sendo que a pesquisa abrange o acompanhamento dos informantes e de algumas dessas famílias na capital e também destes na convivência com suas famílias no interior.

Através das imagens verificam-se as transformações no estilo de vida ${ }^{3}$, na construção de uma etnografia onde há interlocução conceitual reflexiva com os informantes. 
O uso da câmera fotográfica foi negociado e vivenciado de forma diversa entre os informantes. Alguns se mostrando tímidos frente à possibilidade de serem fotografados, outros "encenando" para o momento em que a câmera se voltasse para eles e por fim aqueles que se mostraram irredutíveis quanto ao fato de terem seus rostos fotografados, permitindo apenas que fossem realizadas fotografias da sua moradia. Alguns estudantes também colaboraram com fotografias do período em que moravam com a família para que se pudesse ter maior dimensão de como era sua experiência de vida no interior. A utilização do nome verdadeiro dos informantes foi autorizada por todos eles, assim como a permissão em citar as suas cidades de origem.

As entrevistas semi-estruturadas foram realizadas com os estudantes universitários e também com seus familiares, a fim de perceber como é o processo de negociação, os conflitos existentes e a construção de um projeto familiar em torno da decisão de que os jovens saiam de casa para cursar uma faculdade. As respostas eram livres com intervenção do pesquisador para processar a comunicação e diálogo mas buscando, sempre que possível; deixar o informante falar livremente e por isto a importância da gravação e do diário de campo. Através das respostas que o pesquisador recebe em campo quando faz uso de entrevistas semi-estruturadas é possível perceber os ideais familiares e individuais o que permite se aproximar assim das motivações e intenções por trás das ações. As entrevistas foram anotadas na forma de construção de diários de campo.

A utilização das histórias de vida dos informantes é necessária para a construção de suas trajetórias de vida e compreender aspectos subjetivos da vivência de cada um, dentro de um sistema de valores e de representações que digam respeito a como se construiu um projeto de vida familiar de vir estudar na capital. As histórias de vida foram construídas ao longo de diversas entrevistas e principalmente conversas informais com os estudantes.

\footnotetext{
3 "A construção de narrativas através da imagem fotográfica vem, ao ser articulada com o texto verbal e a legitimidade que este alcançou, contribuir no sentido de enriquecer e agregar, além de outras formas narrativas como a literatura ou a poesia, complexidade aos esforços de interpretação de universos sociais cada vez mais densos e complexos, onde imagens por sua vez tornam-se cada vez mais um elemento da própria sociabilidade". (ACHUTTI, 1997:38-39)
} 


\section{Estudar na UFRGS}

A Universidade Federal do Rio Grande do Sul foi o universo selecionado para a pesquisa. A UFRGS é reconhecida e almejada nos projetos de vida que incluem a passagem pela universidade por sua excelente qualidade ensino público federal universitário e gratuito, sendo que a procura pelas universidades particulares é muito menor, devido aos custos que estão envolvidos e a qualidade do profissional a ser formado que está sempre sendo questionada por significar para muitos que há apenas uma relação conhecimentodinheiro, excluindo aqueles que não possuem capital econômico suficiente. As universidades privadas então são uma segunda opção para quem não ingressa no ensino gratuito.

A UFRGS tem matriculados efetivamente mais de vinte mil alunos somente nos cursos de graduação, desses grande parte não moram com a família de origem em Porto Alegre ou também no Rio Grande do Sul.

A importância de realizar a formação superior na capital e especialmente na UFRGS é um diferencial para esses estudantes justificado pelo reconhecimento da universidade. Ser reconhecido como aluno da UFRGS é ser percebido como alguém esforçado e competente, tanto por ter ingressado na universidade como por ter se mantido dentro dela, fator que é muito prestigiado ao término da faculdade, quando os estudantes voltam para o interior ou procuram aqui na capital a chance do primeiro emprego.

\section{Morar em Porto Alegre}

Porto Alegre tem mais de um milhão e meio de habitantes e é caracterizada por ser uma "capital cultural", com cinemas, exposições, livrarias, entre outros espaços de lazer e cultura. A heterogeneidade também é característica desta metrópole, habitada por pessoas que vem de todos os lugares e contribuem para formar essa diversidade.

A procura por morar em Porto Alegre vem crescendo através, principalmente mas não só por eles, dos jovens, que se distanciam do seio familiar para buscar oportunidades de estudo e profissionais. Mas o desejo de morar em Porto Alegre não é somente fruto da busca do conhecimento e de um futuro profissional. 
Muitos jovens deslocam-se para cá devido a cultura de esquerda e de contestação política que se faz muito presente aqui e pelo estilo moderno e urbanizado da cidade, tudo isso somado, são características que fazem de Porto Alegre um local que agrega jovens do mundo inteiro, que se transferem para cá primeiramente para estudar e acabam por se integrar nas séries de movimentos de cunho contestador da sociedade capitalista atual.

No casos dos jovens informantes na pesquisa a primeira etapa que precisaram enfrentar para morar em Porto Alegre foi passar no vestibular. Dois deles haviam estudado em cursinhos pré-vestibular em cidades próximas daquelas onde residiam com os pais antes de vir para a capital prestar vestibular, os dois passaram no primeiro vestibular que realizaram na UFRGS. Um dos informantes freqüentou cursinho pré-vestibular aqui em Porto Alegre por dois anos, passando então no terceiro vestibular que realizou na universidade.

Superada a etapa do vestibular chega a hora de transferir-se para a capital a fim de iniciar o ano letivo. As opções de moradia são diversas e cada família procura adequar os filhos àquela que lhe parece a melhor, por ser próxima à universidade, aos parentes ou por questões financeiras. Apenas dois estudantes escolheram a moradia sem a presença dos pais, nos demais casos a presença da família foi fundamental na primeira escolha, como é o caso de três dos estudantes, que moraram com parentes. No entanto, depois de certo tempo, quando decidiram não mais ficar próximas aos parentes a família também não teve interferência quanto aos locais das novas moradias, pois entendiam que já conheciam o suficiente em Porto Alegre para que tomassem a decisão de escolher um "bom lugar", caracterizado pela proximidade da universidade e que satisfizesse também as necessidades diárias além de ser um local relativamente seguro para uma cidade grande.

\section{O que é cidade do interior}

É importante ressaltar que nessa pesquisa há uma estudante, que não provêm de uma cidade característica do interior, portanto, o fato de ter sido escolhida como informante nesta pesquisa é porque sua origem é de fora da região metropolitana desta capital, o que faz com que as características vivenciadas no seu processo de deslocamento se igualem as dos demais estudantes, com conflitos devido a distância da mãe e das irmãs e por causa de seu objetivo e escolha de cursar faculdade na UFRGS e não em universidades federais ou estaduais de São Paulo. 
No caso dos demais estudantes é importante significar o que é morar no interior. Todos são de regiões colonizadas por imigrantes alemães ou italianos o que dá as características das cidades, todas com forte apego a religião e família: "O meio me fazia infeliz, a sociedade não é mais como eles pensam, lá eles têm vergonha de tudo”, ou ainda, “Em (cidade de origem) o povo é muito tradicional, voltado para a família, tem que se cuidar em tudo senão já sofre preconceito”. Esses trechos de entrevistas revelam um pouco a oposição que os estudantes fazem das cidades de onde vieram em relação a Porto Alegre, falando do rigor que existe em torno da moralidade e do aceite de outras visões de mundo.

A vida que se tem no interior é muito mais associada a família. O apego e a necessidade de se estar próximo a família são muito salientes e percebidos como uma forma de manter a união entre os seus iguais. O círculo de amigos no interior é composto pelos iguais, ou seja, mesma classe social, mesma escola, mesma cor, e algumas vezes mesmo bairro. Além de tudo, o controle dos pais sobre os amigos do filho também é intenso e a relação entre um filho com um amigo que não é "de boa família" pode ser difícil de ser levada adiante, assim como na vida afetiva. O valor depositado no trabalho como forma de medir a dignidade e competência das pessoas também é uma característica que marca fortemente a sociedade interiorana, onde todos se conhecem e controlam as vidas uns dos outros.

O projeto de sair do interior para muitos jovens significa, além de distanciar-se do controle familiar, ter uma nova visão de mundo, impulsionada pela vontade de conhecer o novo numa cidade que se apresenta com muita diversidade e com o diferencial de possuir uma das melhores universidades federais do país, ou seja, a ânsia pela novidade é somada com a vontade de ingressar em uma universidade de qualidade, que tem como objetivo principal o conhecimento e não apenas a formação para um mercado de trabalho competitivo.

Os jovens que optam por realizarem sua formação universitária próxima ao seio familiar geralmente tem uma dependência sentimental maior pelos pais e fazem a escolha de ingressar em universidades privadas para não serem eles privados do acompanhamento dos familiares. Esses estudantes, em sua maioria não têm a oportunidade de dedicar-se somente aos estudos e necessitam trabalhar para ajudar ou custear integralmente a faculdade a qual se dedicam. 


\section{Uma vez na capital}

Na capital a primeira fase, a de adaptação é difícil no que diz respeito a saudade da família, porém há que se pensar também que é a fase das novidades, de conhecer amigos, lugares e das primeiras modificações no estilo de vida.

Os retornos para casa no primeiro ano de estadia aqui na capital são privilegiados semanalmente, ou no máximo a cada quinze dias. A dificuldade em desligar-se da família e dos amigos que ficaram no interior e o medo do ficar aqui sozinho nos finais de semana impulsionam todas essas idas, principalmente daqueles estudantes que estão morando com parte da família e que mesmo tendo amigos na capital não se sentem a vontade para levalos para o apartamento que na maioria das vezes é do parente com o qual está dividindo.

À medida que o tempo vai passando, com a construção de uma nova rede de amigos na capital e do sentimento de pertencimento ao ethos universitário com todas as suas exigências de dedicação, o estudante acaba se distanciando do interior por perceber que já não tem a mesma visão de mundo de quando estava lá, assim como, os seus próximos que ficaram lá continuam com o mesmo estilo de vida, o que causa conflitos nas idas e voltas dos estudantes, por não se sentirem mais pertencentes aquele lugar.

Esse novo estilo de viver, que confronta o do interior, torna-se aparente nas roupas que o estudante passa a vestir aqui na capital, geralmente mais baratas e não seguidoras da moda atual e que são associadas também as novas percepções que se passa a ter sobre o sistema econômico, a política ou a um estilo de vida hippie, punk ou simplesmente alternativo. Muda também a percepção quanto a solidão, que passa a ser necessária em alguns momentos, frente a todo o estresse diário enfrentado na cidade grande e vista como um momento fundamental tanto para estudo quanto para descanso.

Nessa segunda fase, após o primeiro ano os jovens invertem a situação anterior de idas semanais ao interior e passam a ficar aqui na capital o maior tempo possível, em geral retornando para a casa dos pais uma vez por mês. Essa mudança geográfica dos estudantes faz parte então de um projeto familiar de adquirir ensino de nível superior. A transferência de moradia do jovem provoca alterações na relação familiar devido à distância que se impõe e traz consigo diversos níveis de determinação social, cultural, econômica e afetiva, sobretudo, no novo estilo de vida desse estudante na capital, como contexto de centro universitário com potencialidade para a construção de uma carreira profissional competitiva no mercado de trabalho. 
Conforme os autores Peter Berger e Thomas Luckmann (1997) a vivência no seio familiar é responsável pelo processo primário de socialização do indivíduo. A socialização percebida como necessária para a construção de uma identidade social, onde nos damos conta do papel que devemos desempenhar e nos transformamos em um "personagem" dentro da realidade objetiva, faz parte de um projeto familiar em que todos estão envolvidos para conquistar um objetivo construído conscientemente.

Essa socialização primária, iniciada na infância e junto com a família, vai sendo substituída pela socialização secundária, no caso desses estudantes, quando decidem seguir um projeto de vida na capital, longe dos pais, e passam a interiorizar saberes específicos e papéis que os orientem a uma profissionalização, sendo assim saberes diversos daqueles da socialização primária, da qual a família é a responsável.

Para estes autores, a socialização secundária, a medida que os jovens deslocam-se para a capital, às vezes entra em conflito com a socialização primária, mas também podem não haver disparidades e a socialização secundária passa a ser um prolongamento da socialização vivida junto aos pais sem que hajam rupturas marcantes nessa identidade que está sendo construída.

O novo papel dos estudantes dentro do projeto familiar é construído na socialização secundária em um contexto universitário distante do contexto familiar de origem, onde suas visões de mundo são modificadas e sua identidade vai sendo reformulada nesse processo. No Rio Grande do Sul, Porto Alegre mantém-se o pólo predominante de formação de capital cultural em vistas a um projeto de ascensão social de famílias de camadas médias. Neste sentido o esforço de um exercício etnográfico que busque problematizar a partir de estudo sobre trajetórias pessoais de estudantes, estas escolhas e processos de construção de projetos de vida.

Com a utilização das histórias de vida para a construção das trajetórias foi possível perceber, aspectos sobre o projeto de vida desses estudantes, no que diz respeito ao "ethos intelectual universitário" (VELHO, 2003), a influência da família na construção desse projeto e as próprias percepções do estudante quanto ao seu papel no desenvolvimento desse projeto de estudos. "A noção de que os indivíduos escolhem ou podem escolher é a base, o ponto de partida para se pensar em projeto" (VELHO, 1981:24). 
A trajetória que levará o indivíduo a uma formação universitária é percebida como um investimento que as famílias fazem e que a partir dessa condição o estudante tem a responsabilidade de levar adiante o projeto familiar e afirmar-se na sociedade (FORACCHI, 1972). O projeto de cursar uma faculdade constitui-se num meio para a aquisição de capital econômico e cultural, uma forma de distinção dos demais atores sociais (BOURDIEU, 1989). A importância da família é percebida também nas experiências diversificadas que ela proporciona conforme seu ethos e visão de mundo, que de certa forma o ajudarão a ter consciência do projeto o que levará a uma maior elaboração do mesmo, tendo clareza da sua individualidade nesse projeto. Sair da casa dos pais, principalmente quando essa decisão é tomada voluntariamente "marca e enfatiza a existência do indivíduo enquanto sujeito moral, unidade mínima significativa que se destaca para fazer sua vida" (VELHO, 1981:48).

Dentro do projeto de vida a trajetória do indivíduo é importante por ser um elemento que constitui a sociedade na medida em que na sociedade moderna individualista a noção de biografia individual é fundamental como forma de relevar as experiências do indivíduo dando o sentido da sua singularidade enquanto ator social. O projeto está ligado à idéia de indivíduo-sujeito, ou seja, é indivíduo-sujeito aquele que faz projetos (VELHO, 2003).

Associado ao ato de fazer projetos está a importância da memória que fornece indicadores básicos do passado e do presente para que possam dar consistência ao projeto, dessa forma memória e projeto são articulados para dar sentido à vida e às ações que os indivíduos irão tomar e juntos possibilitam significar e compreender a trajetória individual.

O projeto de vida aparece também dentro das famílias e na individualidade dos estudantes como instrumento básico para negociar a realidade com os demais atores envolvidos nesse projeto. O projeto "existe como meio de comunicação, como maneira de expressar, articular interesses, objetivos, sentimentos, aspirações para o mundo" (VELHO, 2003).

Uma importante característica do projeto é a sua dinâmica e permanente possibilidade de reelaboração reorganizando a memória do indivíduo envolvido, o que nos permite dizer que os projetos mudam ao decorrer de sua elaboração e são adequados pelos indivíduos na sociedade conforme um "campo de possibilidades" que se apresenta no decorrer da trajetória desses estudantes. 
Cabe atentarmos para a definição socioeconômica ou classe a qual esses estudantes pertencem para que assim possamos identificar as mudanças no estilo de vida como conquista do estudante, expressa no seu desejo de mudar e não devido às condições objetivas de vida na capital e em certa medida termos dimensão da sustentabilidade dos projetos de vida desses estudantes dentro da família.

No Brasil, a construção de um projeto familiar com passagem pela universidade é uma representação recorrente de ascensão nas famílias de classe média, não tanto como se manifesta nas classes baixas, onde é necessário o ingresso muito cedo no mercado de trabalho ou nas classes mais abastadas, pelo fato de se "viver de rendas" e já estar socialmente inserido.

É necessário também que pensemos em que contextos se desenvolvem esses projetos familiares de estudos universitários para os filhos longe de suas famílias de origem. Retomando o contexto socioeconômico, esses projetos estão inseridos em uma determinada classe:

Há situação de classe quando: certo número de pessoas tem em comum um componente causal específico em suas oportunidades de vida, e na medida em que esse componente é representado exclusivamente pelos interesses econômicos da posse de bens e oportunidades de renda e é representado sob as condições de mercado e de produtos ou mercado de trabalho. (Weber, 1971: 212).

Por sua vez, a classe da qual estamos falando é a classe média, que se define enquanto classe conforme determinados valores (projeto familiar, dedicação aos estudos, acesso ao lazer) importante neste trabalho para que seja possível analisarmos a trajetória do estudante enquanto fator que esclareça as mudanças no estilo de vida como conquista sua e não decorrente das condições objetivas que lhe são oferecidas agora na capital. Conforme esclarece a antropóloga Myriam Lins de Barros:

(...) camadas médias definidas a partir das próprias representações sociais dos atores e, servindo-se de conceitos como ethos, visão de mundo e grupo de status, capazes de lidar com as categorias de pensamento do grupo estudado. (LINS DE BARROS, 1987: 21). 
Esses jovens, provenientes de famílias de classe média são motivados ou mesmo forçados a possuírem um projeto de vida, que segundo o define Gilberto Velho, "quando há ação com algum objetivo pré-determinado ter-se-á o projeto" VELHO (1981:26) que passa pela universidade, como forma de ascensão, de aquisição de capitais, segundo Pierre Bourdieu (1996), capital cultural, capital econômico. A classe social em que estes estudantes encontram-se inseridos, percebe o acesso à universidade como forma de distinção das demais classes, principalmente pela possibilidade que se tem de através da universidade ascender socialmente e adquirir conhecimento.

Essa trajetória que os estudantes irão desenvolver — de estudos universitários na capital - encontra-se então calcada sobre a expectativa de adquirir capital, como forma de diferenciação entre atores sociais. A importância da delimitação de classe, no caso a classe média, surge porque é através de seu ethos, de uma cultura ou de um grupo em particular, como nesse caso, que o ator social "interpreta sua experiência e organiza sua conduta", ou seja, é inserido dentro dessa classe que o indivíduo constrói seus valores dentro da heterogeneidade característica da sociedade moderna e busca a concretização do seu projeto (GEERTZ, 1978).

Portanto, os estudantes são definidos aqui como pertencentes a uma classe média devido a um conjunto de características ou a uma identidade de valores, tais como, o projeto de vida envolvendo a passagem pela universidade como principal caminho de aquisição de bens simbólicos, maior dedicação aos estudos do que ao trabalho e às atividades de lazer. Conforme Myriam Lins de Barros, formam um grupo através de representações particulares, que por sua vez estão assentadas na identidade, expectativa e valores acima citados.

Além de inserirmos esses estudantes dentro de uma classe é necessário também que se compreenda quem são eles dentro da sociedade, qual a sua especificidade junto aos demais atores que compõem o meio social, em que fase da vida se encontram neste período. No contexto desta pesquisa a juventude é abordada conforme a perspectiva de ARIES (1981), que considera essa uma etapa intermediária na vida, onde o sujeito está em preparação para a fase adulta, sendo encarada desse modo como um estágio de liminaridade. 
(...) a juventude é uma fase socialmente distinta, que se foi processando no desenvolvimento da sociedade moderna ocidental, mediante a progressiva instituição de um espaço separado para a preparação para a vida adulta.(ARIES, 1981:36)

A juventude, dessa forma, é representada por indivíduos que estão em fase de desenvolvimento de estudos universitários, possibilitado devido a decisão da família ou particular — do próprio jovem, porém com negociação dentro da família — de realização de estudos universitários fora da cidade de origem e, além disso, implicando em morar longe do seio familiar.

Para dar conta desse processo de conflito - não expressando a idéia própria de confronto ou de que não possa haver consenso, mas sim enquanto representação sobre o morar na capital em função de um projeto familiar, tanto por parte da família quanto por parte do estudante que se distancia - que envolve a construção do projeto familiar é importante retomar trabalhos que tratem da mobilidade social, como o de Antônio Sérgio Guimarães, (1990) e Myriam Lins De Barros (1987) que explicitam as mudanças ocasionadas na família que fica no lar de origem e as adaptações daqueles que saem de perto dos pais e encontram formas para dar segmento ao seu projeto individual, além de trabalhar com o conflito geracional provocado pelas oposições entre os projetos dos pais e dos filhos (SALEM, 1980).

Esse conflito entre as gerações fica evidente nesta pesquisa quando há a expectativa dos pais que após a conclusão de curso dos filhos estes retornem para o interior e construa sua vida profissional próximo a família de origem. Essa expectativa é frustrada pela maioria dos estudantes na medida em que se adaptam ao "estilo metropolitano de vida" (SIMMEL, 1973) e passam a contrapor a metrópole com a cidade pequena criando argumentos que embasem a sua permanência capital.

É em função desse estágio de preparação para a vida adulta, referido anteriormente, que irá se desenvolver o projeto familiar: "quando há ação com algum objetivo prédeterminado ter-se-á o projeto” (VELHO, 1981:26). Neste caso o objetivo é que o filho ingresse no ensino superior, em uma instituição federal de boa qualidade e gratuita que por sua vez está localizada longe de onde a residência da família encontra-se estabelecida. 
O estudo é muito significativo na vida de todos os informantes, justificado pela aquisição de conhecimento. A ascensão econômica é lembrada por uma informante que diz já trabalhar bastante na sua área para "ganhar dinheiro logo".

De todos os estudantes entrevistados apenas um deles trabalha como estagiário fora da universidade, enquanto dois estudantes não trabalham e nem possuem bolsas. Os demais estudantes dividem suas tarefas diárias entre os estudos e a bolsa de iniciação científica.

Dando continuidade as percepções acerca da família dos estudantes no interior e para que possamos dar conta da relação intrafamiliar que permanece e qual a dinâmica segundo a qual ela passa a se desenvolver após a vinda do estudante para a capital, faz-se importante perceber o que ele mantém do interior onde há tão pouco morava, procurando encontrar elementos que dizem respeito aos aspectos da sociabilidade estimulados pelo fato de morar em uma cidade pequena e no seio familiar. As diferenças entre o adquirido aqui, investigado através do estilo de vida e o que é trazido do interior estão evidentes na arrumação da casa, na maneira de se vestir, na organização, enfim nas coisas práticas do dia-a-dia.

É através do ethos e estilo de vida socializados na experiência familiar que o estudante passa a construir sua identidade social, pela interação com os outros; e é através dessa socialização primária que o estudante traz consigo para a capital, que podemos ter uma compreensão maior da influência que o deslocamento geográfico, do interior para a capital, trouxe no estilo de vida e na conservação de hábitos que ele já possuía no interior e que mantém na capital. (BERGER e LUCKMANN: 1997)

As impressões afetivas, também devem ser analisadas e ampliam a dimensão da importância do que é transmitido aos jovens e do que eles carregam consigo para a vida que irá se desenvolver longe da família — dada a importância neste trabalho de se verificar a mudança do estilo de vida - mas com a presença constante da mesma na subjetividade que os mantêm, desse modo, ligados ao interior, com laços familiares que permanecem apesar da distância.

A família possui, para esses jovens que se deslocam para a capital, influência direta na construção de uma identidade própria e de uma auto-afirmação que esses estudantes sentem necessidade de ter ao estarem longe da família. As impressões afetivas, intimamente ligadas à trajetória familiar modelam parte da vida do estudante em seu novo lar na capital. 
A relação dos informantes com a família e os amigos no interior sofreu mudanças distintas nos casos estudados. A família é considerada em geral como os pais e irmãos, mas faz-se referência ao contato com parentes. A vinda para a capital trouxe, no caso de três informantes uma convivência muito mais harmoniosa com a família nos momentos de retorno:

“Gosto muito de conversar com meus primos lá do interior, nós temos interesses completamente diferentes, eles falam sobre futebol e eu não entendo nada e eles também não gostam dos meus assuntos, mas mesmo assim eu acho super bom porque aprendo muita coisa de lá (cidade de origem)" Informante 1

"Depois que eu vim pra cá em 2001 eu passei a valorizar muito a minha família, a nossa relação mudou completamente, passei a vê eles diferente e eles também passaram a me respeitar. Até então eu não gostava do meu pai, não gostava mesmo, tinha opiniões erradas sobre o meu pai e a minha mãe, e na falta deles percebi que eu gostava deles e eles também, que se preocupavam comigo” Informante 2

"Agora (depois da vinda para Porto Alegre) quando eu vou pra casa eu posso sair, meu pai sempre deixa o carro comigo, eles até perguntam aonde eu vou, mas não me dizem que não é pra $i r$, antes eles só cediam quando minhas irmãs iam pra casa e ficavam pressionando e distraindo eles" Informante 3

A relação com os irmãos também é importante na decisão de vir para a capital e dar continuidade ao projeto familiar de cursar o ensino superior, iniciado antes dos informantes terem se transferido para a capital. Quatro informantes foram antecedidos por seus irmãos na vinda para a capital e através deles se deram seus primeiros momentos na capital.

A convivência com a família que permaneceu no interior ter se tornado harmoniosa após a vinda para Porto Alegre nesses casos, vai ao encontro de uma diminuição da convivência nos finais de semana com os amigos, mesmo sendo esses três casos exemplos de estudantes que no primeiro ano na capital voltavam para casa todos os finais de semana. Os amigos foram deixados de lado, em privilégio da família, por razões de identidade, ou seja, a justificativa dos informantes é a de que seus amigos que permaneceram no interior ficaram com aquelas idéias e objetivos que eles já ultrapassaram, mantendo difícil o nível da conversa entre eles. O fato desses amigos "não acrescentarem nada de novo" fez paulatinamente com que ambas as partes não se procurassem mais, perdendo o interesse uns pelos outros. 
Em relação à cidade onde os pais encontram-se estabelecidos os estudantes tem hoje representações comuns, como a não perspectiva de futuro, as pessoas marcadas por atitudes preconceituosas e a certeza de parte de alguns deles de que a cidade jamais irá sofrer modificações a respeito das pessoas. Devido a isso, apenas um estudante tem planos de talvez voltar para o interior se tiver a oportunidade de fazer algum concurso público e morar próximo aos pais.

Após a trajetória dos estudantes ser construída na pesquisa, as mudanças de estilo de vida dos estudantes passaram a ser analisadas a partir do momento que se dá a vinda para Porto Alegre.

A mudança no estilo de vida, que acompanha a mobilidade geográfica, ocorre em diversas dimensões da vivência do estudante aqui na capital, as mais evidentes entre esses jovens estudados dizem respeito à interação com os amigos, os locais que passam a freqüentar e especialmente modificações ligadas ao novo lar.

A faculdade e seus encargos ocupam grande parte do tempo dos estudantes e é nesse meio que se encontra, em geral o círculo de amizades, estendido também para os momentos de lazer. As diversas opções de uma cidade grande em relação ao local de onde o estudante veio também são sempre mencionadas, e a universidade se caracteriza como uma oportunidade de constituição de identidade longe da família, mesmo que com seu amparo. Os sentimentos de desvinculação aparecem ligados ao de individualização e da noção de que se está diante da possibilidade de escolher os próprios rumos a serem tomados (VELHO, 1981). As representações e sentimentos sobre Porto Alegre aparecem no discurso dos estudantes e convergem principalmente nos aspectos das oportunidades oferecidas:

"Aqui o mercado de trabalho é muito melhor, se tem mais oportunidade. Eu gosto muito de morar aqui porque tem muitos programas culturais, muitas opções e também porque gosto muito dos meus amigos". Informante 4

"Aqui se tem muito mais oportunidade de conhecer as pessoas, e conhecer como elas são porque ninguém precisa se esconder como numa cidade do interior. Eu conheci muita gente aqui e gosto de sair sozinho para conhecer sempre gente diferente. No início, na faculdade e nas festas sempre ia sozinho para conhecer alguém". Informante 5 
"A faculdade foi outro ponto chave, além de eu ir morar sozinho, que me fez ver a vida de outro jeito, com visão de futuro e mudança na minha personalidade, me desencanando sobre várias coisas". Informante 2

Esses são valores essenciais do individualismo moderno e do sentimento de autonomia e liberdade que caracterizam o novo estilo de viver desses estudantes expressados em suas falas. A autonomia, distância do controle moral, a responsabilidade e construção de projeto individual, que são marcos na trajetória do sujeito quando este se destaca para planejar a sua vida, passando a ter consciência da sua exposição a experiências diversificadas e diversas visões de mundo, que contribuirão para o desenvolvimento e reformulação permanente do projeto inicialmente construído com a família.

Estes aspectos são constitutivos de gestos e hábitos diferenciados e de rupturas com as do estilo de viver no contexto familiar no interior. Pode-se observar, por exemplo, que transportados para dentro de seus lares na capital verificam-se mudanças de estilo de vida principalmente na arrumação da casa, onde a manutenção das características da antiga moradia se verifica nos rastros do estudante. O fato de morar sozinho ou dividir apartamento ou quarto implica numa adaptação dos estilos dos moradores à vivência em comum.

Dois estudantes possuem apartamento próprio, pago pelos pais o que permite com que façam modificações que contemplem inteiramente seus gostos. Um estudante mora sozinho num apartamento de um quarto comprado de segunda mão por sua família e reformado a seu gosto. A arrumação, disposição da mobília e cores foram planejadas por ele sem qualquer interferência da família, seus pais vieram para Porto Alegre somente no dia da definição da compra do apartamento e após somente mandavam o auxílio financeiro para que fossem comprados os móveis e utensílios para o apartamento.

Seu lar não possui, conforme ele, nenhuma característica da sua casa no interior "acho muito bom poder arrumar as coisas do meu jeito, fazendo uma coisa que tem tudo a ver com a minha personalidade”, diz que a única coisa que mantém aparentemente como a casa no interior é a disposição dos porta-retratos na sala, na estante que fica de frente para o 
sofá, mas ressalta que a quantidade de fotografias que há na casa no interior é infinitamente maior, sendo que aqui há somente dois porta-retratos com a foto da única sobrinha.

Morando sozinho se sente a vontade também para levar seus amigos na sua casa e gosta muito disso, apesar de sentir necessidade também de ficar sozinho, situação essa que mudou muito em relação a quando morava no interior, que sentia-se rejeitado em não ter ninguém por perto e agora gosta de ficar só mesmo nos finais de semana, assistindo filmes e lendo.

O outro estudante mora em apartamento próprio que divide com o irmão mais velho. A relação dos dois tem algumas tensões, por diferirem muito na maneira de pensar, informante diz que o irmão é egoísta e não aceita a ajuda de ninguém, além de ser muito introspectivo. $\mathrm{O}$ fato de terem que morar juntos faz com que de alguma forma sejam criadas regras entre eles e que fiquem bem explicitadas pela casa. Nas observações que realizei na casa desse informante pude perceber algumas dessas regras na cozinha e na sala. Logo acima da pia encontravam-se os dizeres: "Não deixar louça suja" e "Secar a louça", na sala: “Desligar o computador quando não estiver usando".

O lar na capital mantém as mesmas características que a casa dos pais no interior, isso porque a presença da mãe na capital é constante e o apartamento é arrumado conforme os gostos dela e com objetos escolhidos por ela: "a gente entende que ela se esforça, vem aqui e não pára então a gente acaba deixando ela fazer como ela quer”. Além da mãe do estudante estar mensalmente presente aqui na capital há a presença da família da mãe, suas tias e a avó, todos morando próximos.

A mãe aqui em Porto Alegre altera a rotina porque costumam sair para fazer compras - quem vai ao supermercado fazer as compras do mês é sempre a mãe - , ir a algum lugar que a mãe gosta, aproveitar para assistir um show ou ir ao teatro, além de trazer lembranças do passado, “a comodidade, o carinho, as facilidades de se ter uma mãe em casa”.

A mudança de estilo de vida acompanhada da mudança geográfica fica muito explicita nas atitudes dos estudantes em relação ao lazer. As possibilidades são inúmeras e agradam a todos os gostos. 
Começar a sair intensamente à noite, independente do dia da semana, ato sequer possível em algumas cidades do interior, e sem o controle de horários por parte dos pais é um ponto alto de alteração do estilo de vida. Os lugares que os estudantes freqüentam são os mais variados, como festas de faculdade, danceterias, bares, teatros e festas na casa de amigos ou colegas, que normalmente também não moram com os pais.

O ingresso em ONGs, trabalhos voluntários e movimento estudantil também pode ser percebido como mudança no estilo de vida dos estudantes. A adesão a esses grupos se dá normalmente por convite de amigos que conheceram aqui e que são ou não do interior.

A questão da moradia é vivenciada em todos os casos como o ápice de uma mudança de estilo de vida em relação ao interior. Mesmo aqueles estudantes que continuam morando com parte de família são tomados pela responsabilidade que envolve o fato de morar longe dos pais, como a administração dos recursos financeiros e resolução dos problemas comuns no dia-a-dia.

Os estudantes que passam a dividir moradia com amigos ou pessoas que conheceram na mudança para Porto Alegre têm que conviver ainda com o estilo de vida dos outros moradores, procurando, cada qual manter um equilíbrio que permita o mínimo de convivência.

Três estudantes são as que dividiram apartamento com um número maior de outros estudantes ao mesmo tempo e todos eles conhecidos aqui na capital. Uma das informantes, quando saiu da casa da tia depois de um ano na capital, passou a morar com três pessoas uma moça e dois rapazes - que conheceu através de seus amigos daqui de Porto Alegre. A relação entre eles sempre teve algum problema, "quando não era briga com um era com outro, sempre naquele clima". Esse "clima" ao qual ela se refere diz respeito as constantes brigas dela com algum dos moradores por causa das compras do supermercado que eram deixadas a fazer, a omissão na limpeza do apartamento, o barulho nas horas de estudo, entre outras. O companheirismo desses mesmos moradores com os quais aconteciam as brigas também é salientado pela informante, pois nos momentos que estavam “de bem", costumavam sair juntos para as festas, ir ao cinema ou passear no parque. $\mathrm{O}$ estilo de vida em relação ao lazer realmente modificou-se, se comparado ao do interior, quando passou a morar longe da tia e num bairro com grande concentração de jovens. Antes, a manutenção 
do ethos familiar, era muito mais percebida em função dos serviços diários na creche comunitária e da intensidade de dedicação a seus encargos nos ofícios da Igreja a qual está ligada.

A outra estudante atualmente mora com duas amigas que conheceu aqui em Porto Alegre, uma delas é colega de curso e a outra é conhecida de sua colega. Há pouco tempo atrás dividiam o apartamento com duas pessoas a mais e a relação era muito conflituosa, e acabou se criando uma divisão, as três de um lado e as duas de outro. A diferença no estilo de vida se impôs de maneira tão severa que antes das outras duas colegas de apartamento resolverem sair "os dois grupos" não se olharam e nem trocaram palavras por três meses. As questões mínimas que a divisão de moradia impunham não estavam mais sendo bem resolvidas entre as cinco. As dificuldades que estavam presentes eram a manutenção da limpeza, o barulho, as pessoas que eram levadas para dentro de casa, o espaço que cada uma ocupava, os objetos deixados fora do lugar e a organização da casa. A relação entre os dois grupos formados sempre fora meramente convenção imposta pela divisão de custos, o lazer, os amigos, a vida social não eram compartilhados.

A terceira informante, que também dividiu apartamento com mais quatro pessoas, ressalta que a relação teve "altos e baixos". No primeiro ano - ao todo foram dois anos - a relação era amigável, com divisões de tarefas e cumprimento das mesmas e programas de lazer comuns. Decorrido o primeiro ano iniciaram-se as desavenças devido a "intromissão" da mãe de uma delas nas questões do apartamento, que conforme a percepção da informante, deveriam ser resolvidas por elas. As férias em Porto Alegre, da mãe da companheira de moradia acabaram por criar uma situação constrangedora dentro do apartamento, levando a uma divisão extremada de tudo o que era particular, ou seja, de cada uma, mas usado por todas. A partir desse momento o conflito dos estilos de vida foi cada vez mais acirrado e menos suportado umas pelas outras: "Cada uma queria as coisas da sua maneira e era só alguém mudar que a outra já ia lá e colocava tudo como ela queria de novo", era uma disputa para ver quem teria mais força e também para saber quem teria mais capacidade de agüentar a situação criada. Continuar a morar por quase mais um ano no apartamento após o episódio foi apenas pela necessidade financeira que se impunha. 
No espaço além do apartamento esses estudantes têm seus grupos de amigos e é essencialmente com esses outros estudantes que passam grande parte do tempo quando não estão dedicados aos estudos.

Em Porto Alegre a presença dos amigos adquire outros significados daqueles atribuídos no interior. Aqui os amigos freqüentam assiduamente a casa uns dos outros e reúnem-se para várias atividades, que acabam se tornando momentos de lazer, como fazer um almoço, dedicar-se a algum trabalho voluntário em grupo, ajudar na reforma ou mudança dos amigos além claro, de freqüentarem os mesmos bares e festas.

Entre os estudantes entrevistados também há mudança na perspectiva de independência financeira. Quando se transferem para a capital esses estudantes almejam não depender dos pais, apenas um estudante alcançou inteiramente esse objetivo até então, os demais dependem totalmente ou parcialmente de ajuda de custo da família, mas colocam as duas situações como constrangedoras, especialmente para aqueles que estão próximos do período da formatura. A possibilidade de depender apenas parcialmente do auxílio da família ocorre quando os estudantes obtêm bolsas de estudos fornecidas pela universidade ou instituições financiadoras de pesquisa e ensino.

O estilo de vida dos jovens é reformulado como correspondência a uma nova situação de vida, que permite certo grau de independência, por não ter permanentemente o controle dos pais, e, além disso, que faz com que o estudante sinta que está construindo uma identidade própria e autônoma, mesmo que esta construção esteja calcada em parecerse com os seus iguais, o jovem percebe-se como indivíduo, individuação e imitação que exprimem de modo paradoxal a vontade de afirmar a particularidade pela busca da diferença última (BOURDIEU, 1974).

A partir da transferência desses estudantes para Porto Alegre e a mudança de seus estilos de vida pode gerar conflitos com o projeto familiar, onde por sua vez, aqui na capital, passa-se a evidenciar um projeto individual desses jovens, devido aos valores individualistas da vida metropolitana, que liberta o homem em um sentido espiritualizado em contraposição a pequenez e preconceitos das cidades do interior (SIMMEL, 1979).

Os filhos, quando se deslocam para a capital, passam a questionar o projeto familiar de estudos universitários porque este pressupõe somente a conclusão da graduação para a 
formação profissional, o que devido a mudança de percepções e visões de mundo do estudante gere um conflito por consistir em uma ação com determinado fim e a reflexão sobre tudo o que esse processo de estudos universitários envolve é por vezes deixada de lado. Esses estudantes começam a se preocupar com a busca do conhecimento como forma de saber cada vez mais e não meramente de forma mecânica.

O estilo de vida de passar a sair à noite sem o controle dos pais e a iniciação sexual também são pontos que marcam a mudança da visão de mundo desses estudantes. No interior a maioria já saia à noite, mas aqui a possibilidade de sair sem precisar esclarecer aonde vai, qual a companhia, o que bebeu, a que horas retorna faz esses estudantes sentirem liberdade, limitada apenas pelas condições econômicas. Em períodos de poucas provas na faculdade os jovens costumam sair todos os finais de semana e frequientam lugares, como boates GLS impensáveis para seus pais. Todas essas impressões da noite em Porto Alegre e da diferença desta para a do interior e conseqüentemente daquilo que os pais imaginariam sobre seus filhos podem ser sintetizadas na frase de uma das informantes: "se meu pai sonhasse que eu to aqui nesse lugar e bebendo assim ele me deserdava”, evidenciando mais uma vez um conflito entre gerações (VELHO, 2003).

Junto com as festas, com uma nova rede de amigos e com o sentimento de liberdade em relação ao controle familiar há para alguns desses jovens a iniciação sexual que marca mais uma etapa na conquista de uma identidade própria, marcada por percepções completamente diferentes daquelas do interior, onde a moral permeia todas as ações. A iniciação sexual é percebida, aqui, por esses estudantes como uma forma de prazer e oportunidade de conhecer pessoas, não necessariamente um namorado ou companheira para a vida toda. Os tabus em relação à iniciação sexual de maneira descompromissada são superados pela maioria desses jovens, num momento da vida onde o que importa é conhecer sempre mais.

Este trabalho teve por objetivo mostrar como os projetos familiares e projetos individuais são vivenciados pelos seus atores no deslocamento dos estudantes interioranos para a capital a fim de cursar estudos universitários. $\mathrm{Na}$ perspectiva da reelaboração constante do projeto nos deparamos com a mudança de estilo de vida desses jovens no momento em que passam a residir longe da família. É essa aquisição de um novo estilo de 
vida que deve ser pensada como processo de uma nova socialização no caso estudado de Porto Alegre.

Nos casos em que a ruptura com um estilo de vida interiorano são mais aparentes o projeto individual ganha espaço, assim como a consciência sobre esse mesmo projeto. Já em relação a conformidade com o estilo de vida interiorano, mesmo após o estabelecimento do estudante na capital, presencia-se que o projeto familiar continua se impondo a esses jovens, devido a presença constante da família e fazendo com que o projeto de vida do estudante continue sendo o projeto familiar.

Àqueles estudantes que mantém forte vínculo familiar, dando continuidade às relações interurbanas com constantes retornos e visitas aos familiares, tem um projeto de vida que privilegia, além da formação universitária, uma vida fora da metrópole e não prestigiam a liberdade, no sentido da individualidade proporcionada pela cidade grande. Essa sensação de liberdade é valorizada intensamente pelos estudantes que possuem claramente um projeto individual e percebem que o projeto familiar no qual estavam inseridos pressupõe muitas vezes assumir um estilo de vida compatível com aquele que a família espera e não o estilo de vida da sua socialização na capital.

Três dos informantes são estudantes que seguramente optaram por afastar-se da cultura familiar e seus projetos de vida buscam um afastamento cada vez maior em busca da profissionalização. $\mathrm{O}$ estilo de vida adquirido aqui na capital, fortemente influenciado pelo ethos universitário, reelabora os projetos de vida mostrando a incompatibilidade concomitante ao projeto familiar.

Duas informantes mantêm rastros do interior aqui na capital, o que permite que construam parte de suas vivências aqui em Porto Alegre embasadas nessas características trazidas do interior, principalmente no estilo de vida de suas moradias. No que diz respeito a rede de relações e a mudança de estilo de vida compatível com o ethos universitário há grande incompatibilidade com a vida do interior. Seus projetos individuais não expressam grandes conflitos com os projetos familiares.

Conforme as situações que se apresentaram no trabalho de campo e da conseqüente divisão entre os estilos de vida e projetos evidenciados pelos estudantes cabe também colocar a minha própria condição de estudante do interior na capital, onde o estilo de vida 
adquirido pelo fato de residir longe da família e em uma cidade metropolitana fez com que meu projeto individual se sobressaísse em relação ao projeto familiar. A pretensão de uma constante profissionalização e a experiência de morar longe do controle familiar tornou-se incompatível com o projeto anterior da família de que houvesse retorno à cidade de origem.

A escrita sobre a experiência do Outro, no entanto um Outro que me era familiar, me permitiu entender a articulação que se faz necessária entre o trabalho de campo e a construção própria do texto (CARDOSO DE OLIVEIRA, 2000) como forma de apresentar o ato cognitivo que esse processo de campo e de posterior escrita de texto desencadeou, diferenciando-se das escritas de diários e anotações em campo.

A análise no texto etnográfico, onde está presente a teoria e a interpretação dos estilos de vida, dos projetos familiares e individuais, da trajetória e do ethos permitiram-me a construção de um trabalho que demonstrasse a importância dos processos inseparáveis de observação, do ouvir o informante e do escrever distanciada do espaço de campo. Com esse processo, de fases que se complementam, o trabalho vai a adquirindo sentido através da reflexão e do questionamento e a compreensão do grupo estudado toma seus primeiros contornos.

\section{REFERÊNCIAS}

ACHUTTI, L E R. "Fotoetnografia: um estudo de antropologia visual sobre cotidiano, lixo e trabalho”. Porto Alegre, Tomo Editorial; Palmarinca, 1997.

ARIES, P. História social da criança e da família. Rio de Janeiro, Zahar, 1981.

BARROS, M M L. "Autoridade e afeto, avos, filhos e netos na família brasileira". Rio de Janeiro, Zahar, 1987.

BERGER, P e LUCKMANN T. "A Socialização Secundária e a Mudança Social”. In: DUBART, C: "A Socialização: construção das identidades sociais e profissionais". Porto, Porto Editora, 1997.

BOLETIM DO MUSEU NACIONAL. “Individualismo e Juventude”. Rio de Janeiro, PPGAS - Museu Nacional, Comunicação 18, 1990.

BOTT, E. “Família e rede social”. Rio de Janeiro, Francisco Alves, 1976.

BOURDIEU, P. "Condição de Classe e Posição de Classe". In: "A economia das trocas simbólicas". SP, Editora Perspectiva, 1974.

BOURDIEU, P. “Gostos de Classe e Estilos de Vida”.In: Ortiz: “Pierre Bourdieu”. São Paulo, Editora Ática, 1989.

BOURDIEU, P. “Razões Práticas: Sobre a teoria da ação”. São Paulo, Papirus, 1996.

CARDOSO DE OLIVEIRA. "O trabalho do antropólogo: olhar, ouvir, escrever”. In: “ $O$ trabalho do antropólogo”. São Paulo, Editora UNESP, 2000.

CARVALHO DA ROCHA, A L. "A dialética do estranhamento. A reconstrução da identidade social de mulheres separadas em Porto Alegre”. Dissertação de Mestrado. PPGAS, UFRGS. Porto Alegre, julho de 1985. 
CASTILHOS FRANÇA, M C C de. "A cidade narrada na memória dos velhos habitantes de Teutônia (RS): estudo etnográfico da memória compartilhada sobre as experiências transmitidas na relação entre avós e netos”. Dissertação.Porto Alegre: PPGAS/UFRGS,2002.

DA MATTA, R. “O Ofício de Etnólogo, ou como ter “Anthropological Blues”. In:

Nunes: A Aventura Sociológica. Rio de Janeiro, Zahar Editores, 1978.

DURHAM, E. “A caminho da cidade”. SP, Perspectiva, 1973.

FORACCHI, M. "Frustrações dos jovens e orientação do protesto estudantil". In: Florestan: "Comunidade e sociedade no Brasil, leituras básicas de introdução ao estudo macro-sociológico do Brasil”. São Paulo, USP e Nacional, 1972.

GEERTZ, C. “A Interpretação das Culturas”. Rio de Janeiro, LTC Editora, 1989.

GUIMARÃES, A S A e AGIER, M. "Operários e mobilidade social na Bahia análise de uma trajetória individual". In: RBCS, n 13, ano 5 junho de 1990.

GURAN, M. "Fotografar para descobrir, fotografar para contar". In: "Diálogos Antropológicos: Imagem”.Porto Alegre, LAS, PPGAS-IFCH-UFRGS, 1997.

MENEZES, C. "A mudança: análise da ideologia de um grupo de migrantes". Rio de Janeiro, Imago, 1976.

ROSALDO, M. "A mulher, a Cultura e a Sociedade: uma revisão teórica". In: Rosaldo e Lamphere: "A Mulher, a Cultura, a Sociedade". Rio de Janeiro, Paz e Terra, 1979. SALEM, T. "O velho e o novo. Um estudo de papéis e conflitos familiares". Petrópolis, Vozes, 1980.

SAHLINS, M. "Ilhas de História”. Rio de janeiro, Zahar, 1990.

SIMMEL, G. "A metrópole e a vida mental”. In: VELHO, Otávio. “O Fenômeno Urbano". Rio de Janeiro, Zahar, 1979

VELHO, G. "Projeto e metamorfose, Antropologia das sociedades complexas". Rio de Janeiro, Jorge Zahar, 2003.

VELHO, G. . "Individualismo e Cultura Notas para uma Antropologia da Sociedade Contemporânea”. Rio de Janeiro, Zahar Editores, 1981.

VELHO, G. _. "Subjetividade e Sociedade uma experiência de geração”. RJ, Jorge Zahar Editor, 1989.

VELHO, G. . “A Utopia Urbana Um Estudo de Antropologia Social”. Rio de Janeiro, Zahar Editores, 1973.

WEBER, M. “Classe, Estamento, Partido”. In: Ensaios de Sociologia. Rio de Janeiro, Zahar Editores, 1971. 